\title{
DEVELOPMENT TRENDS OF AIR PASSENGER TRANSPORT SERVICES AND SERVICE DISTRIBUTION CHANNELS
}

\author{
M. Rebezova ${ }^{1}$, N. Sulima ${ }^{2}$, R. Surinov ${ }^{3}$ \\ ${ }^{1}$ Transport Clearing House, Bolshaja Gruzinskaja 59, Moscow 123056, Russia \\ Ph.:+007(495)7881215.E-mail: rebezova@tch.ru \\ ${ }^{2}$ Exigen Services Latvia, Strelnieku 9/3, Riga, LV-1010, Latvia \\ Ph.: (+371)671505515.E-mail: sulima@gmail.com \\ ${ }^{3}$ Rosaviaconsorcium, Kadashevskij per. 2, Moscow 119180, Russia \\ Ph.:+007(495)2322516.E-mail:surinov@rosaviaconsorcium.ru
}

\begin{abstract}
Alongside their core service, i.e., passenger transportation, air carriers are nowadays providing numerous extra services, which are not directly related to transport. On the one hand, airlines are enlarging the scope of paid services provided on board an aircraft by, among other ways, splitting the air ticket fee and singling out the costs of such services as catering on board, checkedin luggage, airport check-in, etc. On the other hand, airline companies tend to provide mass services to their sales partners - ground transportation, car rental, insurance, hotel booking, etc.

Provision of both the core and the extra services is closely connected with computerized reservation systems and the corresponding agent and customer access networks. These systems and networks form the basis of IT channels of service distribution.

The present paper analyses the indicators and development trends of air transport services in combination with the development of service distribution channels and the information technologies lying at the basis of such channels. The paper also describes the structure and IT support of distribution channels. The authors have paid attention to the potential qualitative changes in the structure and possibilities of distribution of air passenger transportation services in view of the Next Generation Network (NGN) concept whose implementation has been started in the world.
\end{abstract}

Keywords: passenger air transport services, Computer Reservation System, Global Distribution System, Information Technology, Next Generation Network

\section{Introduction}

Despite the positive trends in the passenger transportation indicators, world's commercial air passenger transport (civil aviation), is going through serious financial difficulties that are caused, to a certain degree, by subjective reasons, but mostly - by objective reasons, of which there are enough: remember, e.g., terrorist acts in New York and Domodedovo, volcanic eruption in Island, the earthquake and the explosion at the nuclear power station in Japan, etc. These are added to by the continuously growing aviation fuel prices, monopoly of airports and air traffic control (ATC) companies, price pressure on the part of the Global Distribution System (GDS) providers, etc. The above allows formulating the problem as follows: over the last couple of decades, the airlines "accumulated" tens of billions of losses. Many of them - the world leaders in passenger transportation - were forced to merge or to take a creditor protection procedure in order to reorganise the business and cut the expenses. Yet, the comprehensive solution to this problem lies in the implementation of additional fee-based services, both related and not related to transport. Development of the core and extra services requires diversification and optimization of distribution channels, putting forward new demands to the information technologies lying at the basis of such channels.

The objective of this research has been to analyze, through a critical overview of numerous publications, the development trends of air-passenger transportation services, and to make a connection between the development problems of the range of core and extra services and those of the distribution channels and the required IT support.

\section{World's Air Passenger Transportation Indicators}

The commercial air passenger transport has reached the pre-crisis level in the last years; 2.8 billion passengers were transported in 2011 [1,2]. The following operation indicators (rounded) were reached in 2011 (cargo transportation included): income and loss - $\$ 590$ billion and $\$ 575$ billion accordingly; weight load factor - over 0.6; staff positions - 32000 000; passenger load factor - approx. 0.8. 
At the same time, the rate of air accidents was reduced to one per 1400000 flights. The carriers paid about $\$ 54$ billion to the providers (airports, air traffic control (ATC), global distribution systems (GDS), etc.). However, the world air transport is burdened by the debts accumulated over the preceding decades, the total amount exceeding $\$ 50$ billion. The aviation safety costs borne by the airlines and their passengers are also high - over $\$ 7$ billion.

It took three years to restore the income that had decreased by $\$ 22$ billion $(6 \%)$ in financial year 2001. In financial year 2009, right after the world financial crisis of 2008, the income dropped again, this time by $14 \%$ ( $\$ 82$ billion), making $\$ 482$ billion. This drop, however, was also compensated - in 2010 , when the overall income of the branch went up to $\$ 554$ billion, and the airlines got the $\$ 18$ billion profit.

The branch restructuring that took place in the "noughties" facilitated the increase in airlines' income and flexibility in the conditions of a crisis.

Table 1.1, based on the data of [2], shows the air-passenger transportation statistics across the years; Table 1.2 shows the income before interest and taxes (passenger and cargo flights and extra services).

Table 1.1. Number of passengers transported in the world (billions of passengers)

\begin{tabular}{|l|c|c|c|c|c|c|c|c|c|c|c|}
\hline Year & 2001 & 2002 & 2003 & 2004 & 2005 & 2006 & 2007 & 2008 & 2009 & 2010 & 2011 \\
\hline $\begin{array}{l}\text { Number of } \\
\text { passengers } \\
\text { (billions) }\end{array}$ & 1.63 & 1.65 & 1.75 & 1.85 & 2.0 & 2.15 & 2.35 & 2.35 & 2.25 & 2.4 & 2.5 \\
\hline
\end{tabular}

Table 1.2. Profit of the world's commercial airlines (\$ billions)

\begin{tabular}{|l|c|c|c|c|c|c|c|c|c|c|c|}
\hline Year & 2001 & 2002 & 2003 & 2004 & 2005 & 2006 & 2007 & 2008 & 2009 & 2010 & 2011 \\
\hline $\begin{array}{l}\text { Profit (loss), } \\
\text { \$ billions }\end{array}$ & $(13)$ & $(11)$ & $(7)$ & $(6)$ & $(4)$ & 3 & 13 & $(16)$ & $(10)$ & 8 & 5 \\
\hline
\end{tabular}

In the longer term, civil aviation should be prepared to transport 16 billion passengers annually by $2050[1]$.

In our opinion, the following circumstances remain as the key reasons for the substantial growth of airlines' expenses and losses, both now and in the near future:

- terrorist acts and systematic increase in the airline's expenses for anti-terrorism measures;

- climate changes (hurricanes, snowfalls, floods) and natural disasters (volcanic eruptions, earthquakes) increasingly often affecting flight schedules, causing cancellations and delays;

- the growing tension in the world, caused by the wars in the Persian Gulf and Afghanistan, "colour revolutions" in North Africa;

- unstable financial and economic situation, especially in the Euro zone;

- high prices for aviation fuel, no decrease being expected;

- monopoly of companies providing services to carriers (airports, ATC, GDS, etc.).

In the shorter term, the airlines' expenses will also increase - due to the EU decision regarding $\mathrm{CO} 2$ emission charge to be paid when flying through its member states; this promises the world's airlines an annual loss of tens of millions of dollars.

\section{Main Projects Implemented by International Organizations and Airlines to Reduce Transportation Costs}

International organisations (ICAO, IATA), state governments, and airlines themselves are implementing serious programmes and measures to reduce air transportation costs, e.g.:

- IATA Vision 2050 concept [1], based on four key principles: stable income, effective infrastructure, effective technologies, loyal customers;

- IATA programme Simplifying the Business [3, 4], promising the annual 18-billion-dollar reduction of airlines' expenses thanks to the simplification of pre-boarding procedures in airports and more efficient information technologies;

- IATA programme Checkpoint of the Future, entitled to substantially reduce the security check time by dividing the passengers into three groups depending on the information available from the existing database, and organizing their passing through one of the three corridors - "Known Traveller", "Normal", and "Enhanced Security" [5, 6];

- liberalization of international regulations, aimed at the implementation of the open skies principle, and the introduction of notification procedure for the use of air space;

- structuring, aimed at the elimination of branch fragmentation (including, e.g., reduction of the number of airline companies); 
- additional safety measures implemented at the expense of state budgets and reducing, to a significant extent, the carriers' expenditure in this sphere;

- straightening of air routes, which has saved the environment from 71400000 tonnes of CO2 emission since 2004, and helped to cut the world's fuel expenses by $\$ 14.7$ billion [7];

- modernization of the air traffic management system: giving up radars and passing over to the new generation ATM system - based on GPS and known as NextGen - that allows navigating by satellite signals instead of radio ranges, thus saving time and fuel, and, as the final result, raising the airports' capacity [8];

- extensive application of the low cost strategy, not only by the discount airlines, but also by the classic airline companies;

- struggle against Internet fraud (world's airlines' loss from cyber crime amounts to billions of dollars) [9];

- launching the electronic ticketing technology, which has already saved up to $\$ 3$ billion for airlines in the world [3];

- launching the electronic multi-purpose document technology, which allows selling additional services on board the air transport, etc.

On their part, the airlines implement considerable projects to reduce costs by raising the decade's performance by $72 \%$, fuel efficiency - by $21 \%$, and cutting the expenses for service distribution channels by $33 \%[3]$.

\section{Development Trends of Extra Services on Air Transport and Revenue Raising}

Airlines' performance cannot be improved by expense-cutting alone - revenue-raising is what ensures development of airlines in the first place.

The main trend in the sphere of raising the revenue of the world's civil aviation is the provision of extra services conditionally divided into two groups:

- extra services directly related to passenger transportation or own activity of the airline companies;

- intermediary services related to re-sale of goods and services of other providers.

The typical extra services of group one are the following services provided by an airline company to other carriers: ground processing, technical maintenance, material and technical support, consulting, charters, on-board catering supplies, duty-free trade, etc.

In the last decade, group one was supplemented with passenger services directly related to transportation yet singled out from the basic fee. The fee is being split, and the "fractioned" services are paid according to a separate price-list. The large losses the companies encountered after 11 September 2011 were the main imperative reason for the development of this type of services [10]. It was then that many US air carriers started charging their passengers for on-board catering, luggage processing, window seats, etc. Thus, the companies could offer a lower transportation fee, yet increase their income from fees of other services the passengers wished to purchase.

Extra services of group two are services that are not directly related to transportation. Those are usually a part of a separate business not related to the airlines' core activity. Such services include selling various goods and services of other providers through the carrier's distribution channels.

As a result, the airline companies started resembling "flying supermarkets", and a new airline revenue management strategy appeared, which was more characteristic of the discount airlines. The essence of this strategy is that the passenger load factor is more important than revenue from transportation sales. The more passengers there are on board, the more extra services can be sold on the flight. The lower the transportation fee, the less service it includes.

Ryanair, with its super-cheap flights and a very wide range of extra services, is the most promoted airline on the European market [11]; already at the end of 2001, its Director General Michael O'Leary formulated the concept of extra revenue - revenue from air ticket sales replaced by revenue from extra services. The general success formula is as follows:

$<$ more partners $>+<$ millions of website visitors $>+<$ millions of passengers $>+$ $<$ aggressiveness $>=<$ high additional revenue $>$.

Ryanair's website is unique for the aviation branch [12]. It rather presents supportive commerce than transportation itself. The company is a leader by additional income, aggressive marketing, and the scope of commercial activity. For the purposes of this research, we introduce a simplified classification of services presented on Ryanair's website into the following main groups:

- services related to air transportation (sightseeing packages; VIP lounges in airports; airport transfer by minibuses; car rental; hotel, guest house and hostel booking; amusement parks and theme parks; railway express to/from Stansted airport (London); guided tours);

- consumer services (foreign currency exchange; home insurance; life insurance; property abroad; resort cottages for sale; Ryanair MasterCard; tourist insurance options); 
- entertainment (Internet services and online games; instant lottery tickets; theatre, concert, and sports events tickets);

- retail trade (catalogue retailing on board; paid advertising; advertising tourist and leisure destinations).

In addition to the above-listed paid services (IdeaWorks analysis [13]), Ryanair collects the following fees according to the price-list:

- card payment fee for all payments made by debit card via Internet or the airline's call centre (except for Visa Electron);

- priority boarding fee (priority boarding is free for passengers booking their flights via Internet);

- airport check-in fee;

- fee for the first, second, and third piece of checked-in luggage;

- excess luggage fee (per $1 \mathrm{~kg}$ ).

Diversification of airline services has led to the long-term trend of frequent flyer programmes evolving into frequent buyer programmes [14] based on the accumulation of "miles" not only for flights but also for purchase of extra services.

The classic airlines and discount airlines use modern IT to manage their revenue ("Yield Management"/ "Revenue Management") [15]. IT are meant to maximize the income by forecasting customer behaviour and demand, segmenting the market, optimizing the prices of various types of services, etc.

Yield Management - one of the basic revenue management tools used in the sphere of air-passenger transport [16-17]. The term was introduced by R.Crandall (American Airlines), who also considered this information technology to be the most important one for transport management in the period of deregulation in the USA [18-20]. Thus, thanks to using the Yield Management technology, American Airlines got an additional revenue of 1.4 billion US dollars within three years at the end of 1980-s.

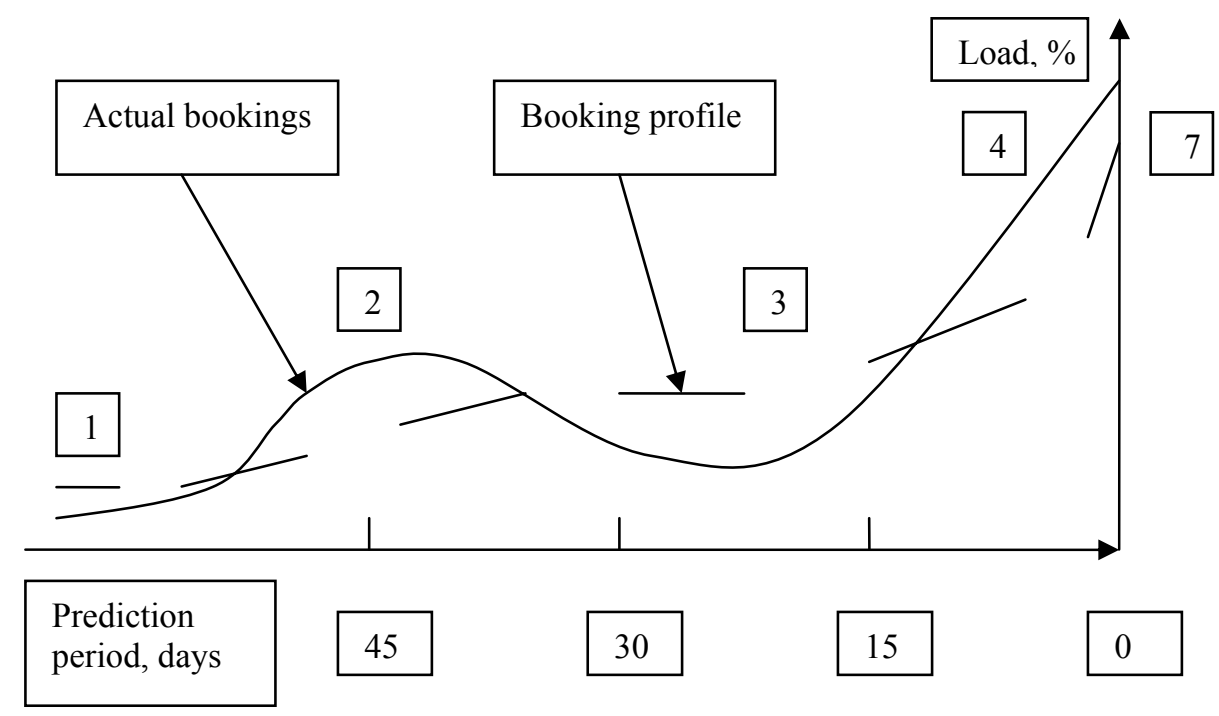

Figure 1. Example of an average and actual booking profile

The essence of Yield Management marketing model is in the following [21]:

Sell the "right" seat to the "right" passenger at the "right" moment for the "right" price.

Figure 1 [22] illustrates the "ideology" of one of such technologies used for seat booking. Being an example of room booking technology in hotel business, it also reflects, in our opinion, the general picture of booking passenger flights.

It is necessary to make the airlines' core and extra services available to the final consumer, i.e., the passenger. This creates another important revenue-raising task for airlines - to diversify distribution channels of such services (enlarge the range of channels).

The "booking profile" line shows the average number of bookings per each interval up to the date for which the booking is made. The "actual bookings" line shows the existing status of bookings as at the date set. The correlation of the two lines characterises the customer behaviour. The two lines moving apart, the management should immediately take certain measures:

- provide discounts or use any other alternative marketing strategy, for it is still a substantially long time till the date for which the booking is made (area 1), or the number of returned seats and non-confirmed booking is large (area 3);

- sell tickets for full price only, to maximize revenue in the conditions of high demand (area 2) or of substantial increase in the number of actual bookings (area 4). 


\section{Diversifying Distribution Channels of the Core and Extra Services of Air Passenger Transport}

We have systematized the channels of distribution of air-passenger transport services and delivery of the services to customers, i.e., passengers, as shown in Figure 2. Marked out are the direct channels (zero level channels), i.e., the channels with no intermediaries involved, and multi-level channels that may involve one or more intermediaries.

Zero level channel presupposes that the carrier sells its services through its own bureaus and representative offices in the online and offline modes. The online distribution it carried out through the carrier's homepage or web-portal. A web-portal is a complex website providing multi-services to customers.

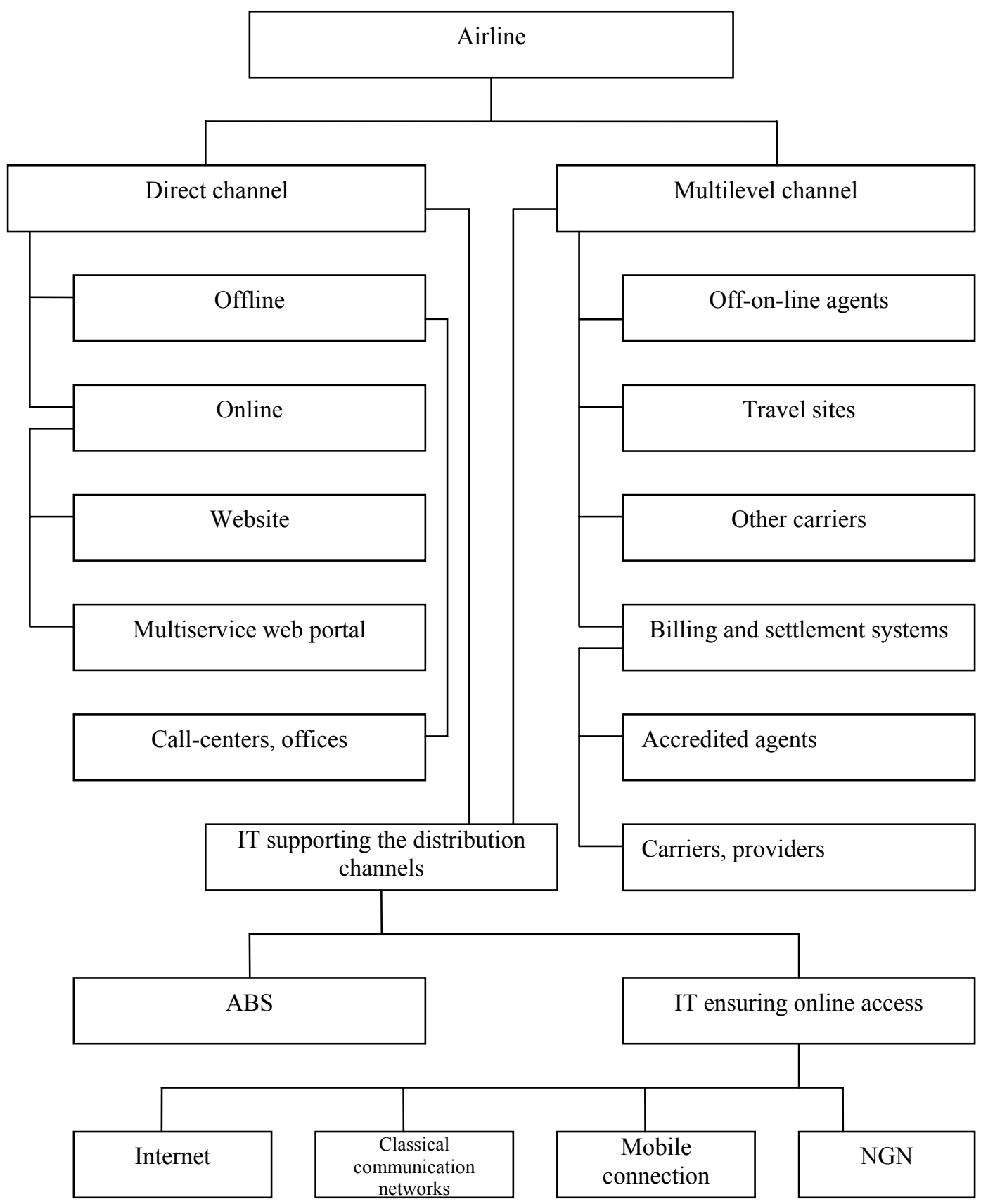

Figure 2. Distribution channels of airline services and IT sales 
The multi-level channels include the traditional logistic chains of a carrier's sales network "offline agents": <agent $>$; <agent - sub-agent $>$; < general agent - agent - sub-agent $>$. An agent's part may be played by another carrier with whom the first carrier has concluded an interline agreement on modal and multi-modal transportation, and who uses his own distribution channels to sell the first carrier's services. It should be noted that agents usually have their own multi-level channels for distribution of their own services.

"The online agents" are those selling flights and extra services only through travel sites. Expedia, Orbitz, Travelocity are among the largest ones.

The travel-site business is developing dynamically. According to forecasts, the volume of travel services booked online in the USA will grow from $\$ 86.6$ billion (2011) to $\$ 110.7$ billion (2014) [23].

Due to the development of the carriers' online sales, the number of agent businesses started decreasing all over the world. Thus, the number of travel agencies in the USA decreased from 27700 (2001) to 15000 (2011). However, direct online booking is becoming less attractive for many Americans. People have no one to turn to for assistance in planning a complex route; besides, the danger of cyber-fraud is growing, which makes people go back to the traditional "offline" and "on-off-line" agents. Thus, in prospect, the traditional agents' business will remain in demand, yet with the tendency towards reduction and enlargement.

In different chains of a carrier's multilevel distribution channel, the carrier's original documents (now including electronic tickets and multipurpose documents) are used alongside billing and settlement systems (BSS) for the processing of flight and extra service sales.

In the last two decades, the world billing and settlement systems have become the most important distribution channels for the services of carriers and other travel industry providers: ARC (Airlines Report Corporation) - mostly in the USA; IATA (International Air Transport Association) BSP (Billing and Settlement Plan) - in the world, except for the USA; CBBT (Air Transport Settlement System managed by the Transport Clearing House) - mostly in the CIS [24]. The BSS are overwhelmingly more important than other distribution channels, for they distribute among the accredited (own) agencies the services of its members - multiple carriers and other providers of travel and tourism services, as well as ensure settlements between all the members for all the core and extra services sold.

The BSS provide the accredited agents and member-airlines with their original standard carriage documents (SCD) for the processing of transportation and extra services sold; the SCD are now 100\% electronic and accepted by all BSS members.

The automated booking systems (ABS) and the IT ensuring online access to ABS form the basis of the IT-based distribution channels.

$A B S$ are divided into the carriers' Inventory systems and the Global distribution systems (GDS), the latter being independent from the carriers. GDS are an extremely powerful distribution channel, but the virtually monopolistic prices they ask for their services contradict the airlines' expense-cutting policy. Therefore, the airlines, having no potential possibility to waive the GDS services due to the high level and diversity of the service range they offer, counterbalance this disadvantage by enlarging their own service range through own inventory systems and trying to limit the agents' access through GDS to their full content (e.g., American Airlines Direct Connect technology [25]). It is, however, impossible for airline companies to refuse the GDS services. The ABS products of the airlines are not yet at the same level as the individual offers and point-of-sale packages of GDS. For this reason, it is unlikely that the volume of GDS services used by airlines will reduce in future, all the more so because even the discount airlines such as, e.g., EasyJet, AirTran, JetBlue, Air Berlin - have now turned to GDS (though on different price conditions) $[26,27]$.

Another future-oriented project is Google's intention to concentrate the Internet travel sales in its "hands", offering more advantageous and comfortable conditions thanks to combining the possibilities of its Internet search engine with one of the best airline fare tracking systems - ITA Software [28]. However, the leading online agents (Expedia and others) are lining up against this project, accusing Google of the breach of anti-monopoly laws.

Access to $A B S$ is ensured both by the classical communication means (ABS units, booking through airlines' and agencies' call-centres and bureaus), and via Internet. It is now also possible to purchase flights and extra services via mobile phones, tickets and documents being drawn up electronically.

\section{Prospects of Distributing Air Passenger Transport Services in the Global Information Society (GIS) - Using NGN Applications}

IT tools, including CRS and GDS, online products, Internet, mobile connection, now also NGN, on the one hand, and carriers, agents with their ticket offices and call-centres, and BSS, on the other hand, open vast possibilities to distribute the core and extra services of air transport through a wide range of channels and respective supportive tools. CRS-providers and GDS invest considerable resources to 
ensure that the developing range of services offered by their customers - airlines and the large circle of subscribers accordingly - can be booked. Even discount airlines have become GDS subscribers, for the latter offered the necessary products for an acceptable distribution price. Such a progressive and, in a way, rapid development of forming, booking, and selling technologies, in combination with the development of the IT-tool range, has led to a certain successive overlap of all these elements [29]. Taking into account the splitting of basic services and fees, mass appearance of new extra services and fees, variety of sales categories and revenue management algorithms, new business models of discount airlines, it can be stated that no entity of the aviation sphere could single-handedly make the whole set of its core and extra services available to the customer.

Basically, the above answers the question why both the growth of online sales and the reduction in the number of traditional agents have slowed down or even stopped. The customer "got lost" in the avalanche of potential possibilities offered by websites. Online booking and purchase of return flight with the whole package of extra services would in most cases be optimal as far as the price is concerned. However, in the case of connecting flights, especially those operated by different airlines with their own sets of extra services, it becomes virtually impossible to optimize the purchase by the price/quality criterion. The customer needs advice, which so far is only available offline, in a traditional agency, from highly professional operators.

In our opinion, the main development trends of airline business will depend on how effectively the following problems are solved: optimization of the structure, diversification and combined use of various distribution channels, adjustment of distribution channels to the ever expanding range of extra services in addition to the core services. New possibilities in this direction are opened by the "information and communication technologies (IT\&T)" that are "one of the most important factors shaping the $21^{\text {st }}$ century society", as stressed by the Okinawa Charter on Global Information Society passed by the G8 leaders in 2000 [30]. GIS throws out new challenges to the developers of information and communication services in all spheres of human activity, including air passenger transport.

NGN (Next Generation Networks) will form the basis of info-communication services in Global Information Society. The essence of NGN is partly explained by the following formula: all kinds of IT\&T services for the user - "from one socket" (integration and multi-service approach) [31].

In our view, the solution to the problem of online sales tempo growth lies in the usage of NGN in combination with an "electronic consultant" (as an IT-application) for multimedia booking of air passenger transport services via CRS and GDS. In other words, the Customer, when booking and purchasing the flight and extra services, is not just "communicating" with the "electronic engine" of the carrier's or agent's website, but also using multimedia products, such as NGN applications for online consulting, ensuring the best choice of services.

\section{Conclusions}

1. There is a substantial trend of growth in the volumes of passenger transportation and airlines' income from all types of services in the world. The trend of growth in the airlines' expenses surpasses the income growth, which creates the negative profit trend; no loss of airlines has accumulated in the world yet. For this reason, international organizations (ICAO, IATA), state governments, and airlines themselves are implementing a complex of programmes and measures to substantially reduce the airlines' expenses related to passenger transportation.

2. Provision of various extra services, both original and offered by other providers, is one of the main trends of the world's air passenger transport in the revenue-raising sphere. This increases the importance of diversification of distribution channels for such services and the IT supporting those channels. The development of online IT-products is facilitated not only by the transition of the whole branch to a fully electronic ticketing procedure within passenger transportation, but also by the transition to electronic multi-purpose documents for the processing of sales of extra services.

3. New "players" are appearing at the air-passenger service distribution market, such as Google, which intends to concentrate the Internet travel sales in its "hands" by combining the possibilities of its Internet search engine with one of the best airline fare tracking systems - ITA Software.

4. We believe that in the near future one should expect the appearance of "electronic consultants" and other multimedia products in the form of NGN IT-applications, meant for booking of air passenger transport services via CRS and GDS.

5. The main development trends of airline business will depend on how effectively the following problems are solved: optimization of the structure, diversification and combined use of various distribution channels, adjustment of distribution channels to the ever expanding range of extra services in addition to the core services. 


\section{References}

1. Speech presented by IATA Director General Giovanni Bisignani at $66^{\text {th }}$ IATA Annual General Meeting and World Air Transport Summit in Berlin on 7 June 2010, from official website of IATA: www.iata.org

2. Source: Centre for Asia Pacific Aviation, IATA.

3. Speech presented by IATA Director General Giovanni Bisignani at the press briefing in Beijing in February 2011, from official website of IATA: www.iata.org

4. Fast Travel Programme IATA - Simplifying the Business, from http://www.iata.org/whatwedo/stb/Documents/Fast\%20Travel\%20Programme\%20Strategy\%.pdf

5. Pavlovsky, A. (2011). Checkpoint of the Future. CNN, 7 June 2011.

6. Press Releases No.: 35. 07.06.2011 IATA Reveals Checkpoint of the Future, from http://www.iata.org/pressroom/pr/pages/2011-06-07-01.aspx

7. Arnolt, S. Flightglobal. (2010, February 16).

8. Lindsay, C. Aviation is the engine of economy. (2011, January 31). New York Times.

9. Jones, C. Stolen Mile. (2010, October, 05). USA Today.

10. "Gold Rush" in the air and on the ground. (2010, February). Airline Weekly.

11. An Offer You Cannot Refuse, from http://www.traveldailynews.gr;

12. http://www.ryanair.com

13. http://www.ideaworkscompany.com

14. Plank, W. The Wall Street Journal online. 5 February 2010

15. Cross, R. (1997). Revenue Management: Hard-Core Tactics for Market Domination. New York: Broadway Books.

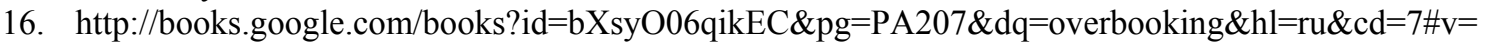
onepage \&q=overbooking $\& \mathrm{f}=$ false

17. http://archive.ite.journal.informs.org/Vol3No1/NetessineShumsky/ Introduction to the Theory and Practice of Yield Management. Serguei Netessine. The Wharton School University of Pennsylvania. Robert Shumsky. W. E. Simon Graduate School of Business Administration University of Rochester

18. Wardell, David J. Understanding Yield Management, from http://www.wardell.org/understanding_yield_management.htm.

19. Best Practice Pricing, from http://bestpracticepricing.blogspot.com/ 8 July 2008

20. Netessine, S., Shumsky, R. (2002). Introduction to the Theory and Practice of Yield Management. INFORM Transactions on Education, 3(1).

21. Randall Beard, Nielsen IAG. What Advertisers Can Learn from the Airlines? Retrieved November 12, 2009, from http://blog.nielsen.com/nielsenwire/online_mobile/yield-management-what-advertiserscan-learn-from-the-airlines/Yield Management

22. http://www.rea.ru/hotel/it/metod/Text/ym.htm

23. All Kinds of Agents Are Useful. (2010, November 15). USA Today.

24. Basics of Air transport settlement system. (2011). In E. Maharev (Ed.), Transport and Telecommunication Institute Study Guide (pp. 67-75). Riga: TTI.

25. Retrieved 2011, March 23 from http://www.aa.com/i18n/agency/General/aa_direct_connect.jsp.

26. Bemer, J. Indicator of Maturity. (2010, June 1). Business Travel News.

27. Kinbi, D. Whose Nerves are Stronger, or what is behind the Conflict between American Airlines and Orbitz. (2011, January 5). Travel Daily News.

28. Lidtke, M., Tessler, D. Google Enters the Battle. (2011, February16). Canadian Business.

29. Kobi, P. One dead, the other gone insane. (2011, March). Airline Business.

30. Okinawa Charter on Global Information Society. (2000). Diplomatic Newsletter, 8, 52.

31. Baklanov, I. (2008). NGN: Build-up and Organisation Principles, Y. Chernyshev (Ed.). M.: Eko-Trends. 